\title{
An Experimental Study on I.C. Engine Using Compressed Air as Alternate of Fuel: A Review
}

\author{
Bhardwajsinh Mahida ${ }^{1}$, Dipak C. Gosai ${ }^{2}$ \\ ${ }^{1}$ PG Student, Mechanical Department, S.V.M Institute of Technology, Bharuch, India \\ ${ }^{2}$ Associate Professor, Mechanical Department, S.V.M Institute of Technology, Bharuch, India
}

\begin{abstract}
Nowadays the global warming is a prime problem for world and automobile industries is increases day by day. Automobile vehicle is main factor to produce many harmful gases like carbon monoxide (CO) hydro carbon (HC) also produce nitrogen oxide (NOx) so in this review some experimental analysis is show that the vehicle which is run on compressed air as alternate of fuel is not produce any type of pollution. Also study about the load calculation at particular pressure in the storage tank and vehicle is run or not compressed air. Some experimental study says about in this review that the some major change is required in I.C.Engine to run on compressed air. A single cylinder light weight four stroke engine is produced more power without any pollution is shown in the review. Compressed air technology to produce power is reducing many crises to change the world. Last few years many researcher works on compressed air engine and last 10 years (2005-2015) researchers review is shown in this paper.
\end{abstract}

Keywords: Compressed air engine, Zero pollution, Emission control, Compressed air as alternate of fuel.

\section{Introduction}

In Automobile vehicles internal combustion engine is widely use and for last few years the automobile vehicles are increases day by day in market so that also increase the demand of fossil fuels. For using this fossil fuel in automobile also increases the problem of pollution in environment. The main pollutant is produced by I.C.Engine is hydrocarbon (HC) and carbon monoxide (CO). I.C Engine is also produce less amount of nitrogen oxide (NOx) and lead. In last ten years the automobile vehicle population is increased and also pollution is increased which create a major problems in atmosphere like global warming, greenhouse effect etc. and also fossil fuel is not a renewable source. For this energy crisis many researcher is developing a new source which is renewable as well as non-polluting. In last few years the many companies and researcher is work on zero pollutant engine. This engine is a also I.C.Engine but this engine has not required any type of fuel like Petrol, Diesel, LPG, and CNG it is work on compressed air power. In this engine the main source is compressed air which is totally pollution free. This type of engine is not producing any type of pollution like $\mathrm{CO}, \mathrm{HC}$, and $\mathrm{NOx}$ this is totally eco-friendly engine. For last ten years many researchers has been work on compressed air engine. In this review study on last ten years papers and found out the conclusion on experimental study on the engine which is run on compressed air as alternate of fuel.

\section{Recent Studies}

Some reviews on compressed air engine have been studied and some experimental analysis such emission characteristics, power production by compressed air, RPM of the compressed air power engine and last but not the least which is load is carried out by compressed air power engine.

In the Study of Ulf Bossel [1], the foregoing analysis may not be the first of its kind and certainly needs refinements. In particular, the thermodynamics of heat exchange, mechanical and aerodynamic losses, electrical efficiencies etc. need to be considered. All these effects may reduce the overall efficiency to $40 \%$ or less. With respect to overall efficiency, battery-electric vehicles may be better than air cars, but hydrogen fuel cell systems may be worse. However, with respect to system and operating costs, air cars may offer many advantages such as simplicity, cost, independence, zero pollution and environmental friendliness of all system components.

In the study of S.S. Thipse [2], the efficiency of electric vehicles from battery to wheel is 80 per cent. If the air compressor is powered by an ICE with an efficiency of about 40 per cent, then the overall efficiency of the air car from fuel to wheel is $40 \% \times 40 \%=16 \%$, which is poor, as compared to an IC engine or battery-electric powertrain.

In the study of Chetan K.Tembhurkar et al. [3], in air engine, the small piston has a conventional connecting rod for turning the crankshaft, while its neighboring larger piston utilizes an innovative rocker arm configuration with the connecting rod. This design allows the large piston to pause at top-dead-centre for 70 degrees of crankshaft rotation while metered air pressure builds in a pre-chamber as the small piston keeps the crank turning during its power stroke. The large piston then turns the crankshaft with greater power as the pair combine to produce power over 270 degrees of crankshaft rotation. Prototype air cars are minimize transportation that typically exhibit a top speed of about 70 mph and a range of approximately 125 miles on flat roads before requiring a refill. Compressed air is stored at 300 bar (4351 psi) in carbon fiber tanks mounted longitudinally beneath the vehicle floor. Refilling can be accomplished in a matter of minutes at a special high-pressure pump or in about four hours via a home re-fuelling appliance or even an on-board compressor.

In the study of Zhenggang $\mathrm{Xu}$ et al. [4], a control system was developed to reduce the exhaust pressure of vehicle compressed air powered engine. The control system is made up of a controller, a pressure sensor, a photoelectric encoder, an inlet solenoid valve, and an exhaust solenoid valve. The

\section{Volume 4 Issue 12, December 2015}




\section{International Journal of Science and Research (IJSR) \\ ISSN (Online): 2319-7064}

Index Copernicus Value (2013): 6.14 | Impact Factor (2014): 5.611

controller receives the pressure signal of compressed air in cylinder form the pressure sensor and receives crank angle signal from photoelectric encoder, calculates when the solenoid valves should be opened or closed, and passes control signals to the solenoid valves.

In the study of Prof. B. S. PATEL et al. [5], the technology is just about modifying the engine of any regular IC engine vehicle into an Air Powered Engine. The Air Powered Engine technology is cheaper in cost and maintenance, can be easily adapted by the masses and it doesn't cause any kind of harm to the environment. Instead, its widespread use will help mankind in controlling the serious problem of global warming.

In the study of Bharat Raj Singh et al. [6], globally excessive consumption of hydrocarbon fuel in transport sector is a serious threat to the civilization due to the paucity of fuel in future. Also this growing use of vehicles for transport is contributing about $70 \%$ of total air pollution and causing environmental and ecological imbalances.

In the study of J.P.Yadav et al. [7], compressed air propulsion may also be incorporated in hybrid systems, e.g., battery electric propulsion and fuel tanks to recharge the batteries. This kind of system is called hybrid-pneumatic electric propulsion. Additionally, regenerative braking can also be used in conjunction with this system.

In the study of Qihui Yu et al. [8], if inlet pressure is much bigger than environment pressure, there is a big expansion ratio to reach the maximum useful work to signal expansion system. So it is necessary to establish two stage expansion systems. Each stage expansion ratio is different to reach maximum output work in two stage expansion system. Expansion ratio of the first stage of the system significantly affected the output of useful work. Two stage expansion ratios will become bigger, if the first stage expansion ratio equal to the second expansion ratio. Pressure is big in gas tank to get higher energy density. So we should use multistage system to obtain the maximum useful work. In order to increase the output of useful work, the first stage expansion should be increased as much as possible to two stage expansion systems.

In the study of Bharat Raj Singh et al. [9], focuses on study of some energy storage and energy conversion systems. Special focus is laid on use of compressed atmospheric air as a viable alternative energy source. Such energy storage system can be used as clean energy source as zero pollution sources, and help in mitigating the global warming. The performance efficiency of the novel compressed air engine is found varying from $72 \%-97 \%$ and is suitable to run motorbike's air engine as zero pollution.

In the study of Mistry Manish K et al. [10], to satisfy there need alternate fuel or energy is required. But while considering alternate fuel some of factors are to be considered like availability, economy, and environment friendly etc., based on that CAT (Compressed Air Technology) is best technology which tend engine to zero pollutions. If further improvement is carried out with stress analysis, thermodynamic analysis, minimize compressed energy loss and other losses then efficiency of CAE may be further increases.

In the study of Rahul Kumar et al. [11], the average output torque and rotational speed increases with the increase of intake pressure. Under the same intake pressure, the average output torque increases with the increase of cylinder bore, but the rotational speed decreases with the increase of it. Above research conclusions will provide significant reference for further study on optimizing design.

In the study of Abhishek Lal et al. [12], the expansion and exhaust of air takes place during single stroke which make it a single stroke engine. Its power output is more than any other compressed air engines, as it is Single stroke engine rate of work done is high. Exhaust gas which is air is clean and cool $\left(5^{\circ} \mathrm{C}\right)$. Manufacturing of light weight engine can be done.

In the study of Anirudh Addala et al. [13], compressed air car is not expensive. Compressed air car is affordable and have a performance rate whose power to weight ratio stands up to $0.0373 \mathrm{~kW} / \mathrm{kg}$.

Chih-Yung Huang et al. [14], the engine was modified from a 4-stroke to a 2-stroke engine using a cam system driven by a crankshaft and the intake and exhaust valves have a small lift due to this modification. The highest power output of $0.95 \mathrm{~kW}$ was obtained at 9 bar and $1320 \mathrm{rpm}$. The highest torque of $9.99 \mathrm{~N} \cdot \mathrm{m}$ occurred at the same pressure, but at 465 $\mathrm{rpm}$. The outlet pressure increased from 1.5 bar at $500 \mathrm{rpm}$ to 2.25 bar at $2000 \mathrm{rpm}$, showing the potential of recycling the compressed air energy by attaching additional cylinders (split-cycle engine).

In the study of Dein Shaw et al. [15], hydraulic system driven by compressed air to demonstrate its potential to outperform a pneumatic motor in efficiency. The major parameter of efficiency under a constant pressure operation is the operating pressure; the efficiency is better with lower pressure. When the air expands in the converter, the residual pressure is also a dominant parameter. Lesser air intake leads to more heat transfer from the surrounding into the converter, thereby enhancing the efficiency. The efficiency of the air/oil conversion can be evaluated through the analysis presented in this paper. Only $0 \%-3.4 \%$ difference exists between the theoretical and experimental system efficiency, which verifies that the analysis is practical to estimate the efficiency.

Naveen Kumar et al. [16], the engine were successfully tested at majorly two pressures. At a lower $\sim 10$ bar with a lower capacity (max. 10 bar) two-way NC solenoid valve and a higher 25 bar with a higher capacity (max. 30 bar) three-way NC solenoid valve. Both valves had a similar delay period of about $20 \mathrm{~ms}$.

In the study of S. S. Verma et al. [17], The storage of compressed air (initially as well as during journey) with all benefits like no heating, high energy density and provisions to make use of cooling produced during adiabatic expansion during the energy release have to be taken care off in a much more controlled manner. Electric-powered cars and bikes 


\section{International Journal of Science and Research (IJSR) \\ ISSN (Online): 2319-7064}

Index Copernicus Value (2013): 6.14 | Impact Factor (2014): 5.611

already available on the market put a strong competition to compressed air car not only in terms of cost but also their environment friendly role. The technology still looks distant but that has not deterred inventors from working on it.

Amardeep et al. [18], there are still some serious problems to be sorted out, like lack of starting torque and cost of compressing air, before air powered vehicles become reality for common use but there is a hope that with the developments in science and technology which are also in agreement with the environment.

In the study of D. Ravi [19], with the present situation of alarming pollution and depletion of fossil fuel, the concept of compressed air engine has taken a vital position in the research and development field. Various improvements in this regard are proving that in near future, the world will witness a much cleaner environment by the practical implementation of such air engine. Thus the potential of air can be utilized as an alternating fuel for the automobiles.

In the Study of Deepak K. Agarwalla et al. [20], the speed of the engine is found to increase almost linearly with the increase in the pressures. Moreover, the torque and power generated also increase linearly with respect to the change in pressure.

Franco Antony et al. [21], the air can also be generated from the air compressor in labs, petrol pumps etc. which refills much faster when compared to the DC compressor. A small compressor can also be brought home for the purpose. It is cost effective while comparing with the fossil fuel and its emissions. Thus the replenishing can be done with a DC compressor, air compressor and from petrol pumps which can be done with less investment.

In the study of Prof. Kalpesh Chavda et al. [22], the theoretical and experimental results showed the advantage of the proposed strategy over the conventional single-storage system. The proposed compression algorithm can be utilized in an air hybrid vehicle to increase the efficiency of energy recovery by the compression braking system. Compared to the double-stage regenerative braking, the double-tank system doubles the air flow rate because only one cylinder is needed to implement the proposed concept and thus, all the cylinders can be connected directly to the main tank. The proposed compression algorithm can be applied not only in air hybrid vehicle compression braking system, but also in any other applications, where higher pressure with higher air mass flow rate is demanded such as typical reciprocating compressors.

In the study of Ruchil A. Patel [23], in power stroke of CAE, High pressurize air via inlet valve, supply to cylinder and it will move the piston from TDC to BDC. Problem concerned to working of this engine at starting, it requires initial torque to be provided by other means to bring engine into motion. In exhaust stroke of CAE, air escape from cylinder via exhaust valve and inlet valve get closed. One interesting benefit is that the exhaust air temperature of C.A.E. measured practically as low as $17.60 \mathrm{C}$ is less than atmospheric temperature.
In the study of S.A. Ahmad et al. [24], At $20^{\circ}$ c, 22 liter tank loaded with air at 8 bar used just $15.6 \mathrm{~W}$ of vitality. Under perfect reversible isothermal conditions, this vitality was totally changed over to mechanical work. Then again, under isentropic conditions (no heat was traded with the environment)that's the reason $15 \mathrm{~W}$ get to be valuable. The consequences of this examination were appeared to show that the effectiveness of the single stage expansion process was worthy, while even a one -stage air compression was associated with noteworthy misfortunes. Nonetheless, the general vitality use was increased on the grounds that the waste high temperature produced during the air compression process was utilized for household water and space warming.

In the study Saurabh Pathak et al. [25], conclude that the compressed air technology can be tested and developed using the Vaned Type Novel Air Turbine as there are minimal losses and practically their efficiency varies from $72-97 \%$ which is very high when compared to a conventional IC engine. Future developments can be made by designing an ideal vehicle for this kind of engine.

In the study Yuan-Wei Wang et al. [26], the compressed air engine was installed on a motorcycle for the demonstration of vehicle application. The success of this application demonstrates the concept of green energy vehicle with zero emission using compressed air energy. The motorcycle installed with the compressed air engine can operate at maximum speed around $38.2 \mathrm{~km} / \mathrm{hr}$. and distance up to 5 $\mathrm{km}$. Even though the operation of compressed air can be integrated with conventional IC engine using the same arrangement with piston and cylinder, the application as main power system on motor vehicles still have the limitation of short range vehicles like golf cars or ATVs.

In the study of Ankit Sharma et al. [27], at small pressure of 10 bar with varying injection angle from $10^{\circ}$ before top dead centre to $15^{\circ}$ after top dead centre, the rotating speed was found to be $715 \mathrm{rpm}$ to $965 \mathrm{rpm}$ whereas, at higher pressure of 25 bar with varying injection angle the speed ranged from $1191 \mathrm{rpm}$ to $1422 \mathrm{rpm}$. At lower pressure of 5 bars the maximum speed was $28.9 \mathrm{kmh}-1$ with a travelling distance of $2.5 \mathrm{~km}$, whereas at high pressure of 9 bars the maximum speed attained was $36.5 \mathrm{kmh}-1$ travelling $1.7 \mathrm{~km}$.

Bilal Abdullah Baig et al. [28], compressed air engine is a modified $100 \mathrm{cc}$ internal combustion engine. The engine is modified from a 4-working stroke to a 2- working stroke engine (power and exhaust) by modification of cam-gear system. The maximum pressure used is 8 bars. A temperature decrease from room temperature to $15^{\circ} \mathrm{C}$ was observed at exhaust.

Mr. N.Govind et al. [29], car will almost certainly use the Compressed Air Motor (CAM). Air cars using this engine will have tanks that will probably hold about 78 litters of compressed air. The vehicle's accelerator operates valve on its tank that allows air to be released into a pipe and then into the motor, where the pressure of the air's expansion will push against the vanes and turn the rotor. This will produced enough power for speeds of about 15-20 kilometres per hour.

\section{Volume 4 Issue 12, December 2015}




\section{International Journal of Science and Research (IJSR) \\ ISSN (Online): 2319-7064}

Index Copernicus Value (2013): 6.14 | Impact Factor (2014): 5.611

\section{Conclusion}

This paper is provides the review on compressed air engine its design experimental analysis as well as new technology and development over the last 10 years. In this paper some new technology is develop like new design of cam for four stroke engine, also provide new technology of fabrication of compressed air vehicle. This review is show some advantages and disadvantages of compressed air vehicle and the experimental analysis like load calculation, power production by engine and main factor is pollution is not produced by this engine. The main key factor is obtained which is shown in below:

- The thermodynamics of heat exchange, mechanical and aerodynamic losses, electrical efficiencies etc. all these effects may reduce the overall efficiency to $40 \%$ or less.

- The speed of the engine is found to increase almost linearly with the increase in the pressures.

- High pressure of 9 bars the maximum speed attained was $36.5 \mathrm{kmh}^{-1}$ travelling $1.7 \mathrm{~km}$.

- The engine is modified from a 4-working stroke to a 2working stroke engine (power and exhaust) by modification of cam-gear system.

- At $20^{\circ} \mathrm{c}, 22$ liter tank loaded with air at 8 bar used just $15.6 \mathrm{~W}$ of vitality.

- The motorcycle installed with the compressed air engine can operate at maximum speed around $38.2 \mathrm{~km} / \mathrm{hr}$. and distance up to $5 \mathrm{~km}$.

- This will produced enough power for speeds of about 1520 kilometres per hour.

- Compressed air engine is not producing any harmful gases for environment as well as human body this is totally pollution free engine.

\section{References}

[1] Ulf Bossel, Thermodynamic analysis of compressed air vehicle propulsion, Journal of KONES Internal Combustion Engines, 12(3-4), 2005, 51-62.

[2] S. S. Thipse, Compressed Air Car, Engine Development Laboratory, Automotive research, Association of India, 2008, 33-37.

[3] C. K. Tembhurkar, and P.D. Kamble, Computer Aided Design and Analysis of Air Engine Piston, G.H. Raisoni college of Engineering, Nagpur University, IEEE Second International Conference on Emerging Trends in Engineering and Technology, 2009, 92-97.

[4] Zhenggang $\mathrm{Xu}$, and Xiaopeng Xie, A Method for Reducing Exhaust Pressure of Vehicle Compressed Air Powered Engine, IEEE,International Conference on Mechatronics and Automation, 2009, 9-12.

[5] B. S. Patel, Mr R S Barot, Karan Shah and Pushpendra Sharma, Air Powered Engine, B.V.M. Engineering College, V.V.Nagar,Gujarat,India, National Conference on Recent Trends in Engineering \& Technology, 2011.

[6] B. R. Singh, and O. Singh, Compressed air energy storage system based engine for running light, International journal of Energy and Environment Technology, 2(4), 2011, 33-44.

[7] J.P.Yadav and Bharat Raj Singh, Study and Fabrication of Compressed Air Engine, S-JPSET, 2(1), 2011, 1-8.
[8] Y. Qihui and C. Maolin, Research on expansion ratio of air power engine system, IEEE, 2011, 987-990

[9] B. R. Singh, and O. Singh, Study of Compressed Air Storage System as Clean Potential Energy for 21st Century, Global Journal of Researches in Mechanical and Mechanics engineering, 12(1), 2012.

[10] M.K.Mistry, P. P. Rathod and A.S.sorathiya, Study and Development of Compressed Air Engine Single cylinder, International Journal of Advanced Engineering Technology,3(1), 2012, 271-274.

[11] R. Kumar and Anand M.G, Simulation and construction of Single-stage reciprocating pneumatic transmission system Engine, International Journal of Scientific and Research Publications, 2(7), 2012.

[12]A. Lal and K. Nagar, Design and Dynamic Analysis of Single Stroke Compressed Air Engine, International Journal of Renewable Energy Researches, 3(2), 2013.

[13] Anirudh Addala \& Srinivasu Gangada, Fabrication and Testing of Compressed Air Car Viswanadha Institute of Technology and Management, Global Journal of Researches in Engineering, 13(1), 2013.

[14] C. Y. Huang, C. K. Hu, C. J. Yu, and C. K. Sung, Experimental investigation on the Performance of a Compressed-Air Driven Piston Engine, Department of Power Mechanical Engineering, National Tsing Hua University, 6, 2013, 1731-1745.

[15] D. Shaw, J. J. Yu, and C. Chieh, Design of a Hydraulic Motor System Driven By Compressed Air, National Tsing-Hua University, Energies, 6, 2013, 3149-3166.

[16] N. Kumar, U. Banka, M. Chitransh, J. Takkar, V. Kumar, U. Gupta, and S. Singh, Compressed Air Retrofit Kit For Existing motor Vehicles, World Congress Of Engineering, 3, 2013.

[17] S. S. Verma, Latest Developments of a Compressed Air Vehicle: A Status Report, Global Journal of Researches in Engineering, 13(1). 2013.

[18] Amardeep, K.Mathur, R.C. Singh, D.Bisht, R.Arora and A.K.Shandilya, Pneumatically Actuated Vehicle as an Alter-Native, International Conference of Advance Research and Innovation, ISBN 978-93-5156-328-0, 2014, 572-574.

[19] D.Ravi, Fabrication of Compressed Air Engine, MiddleEast Journal of Scientific Research, 20(9), 2014, 1075 1077.

[20]D. K. Agarwalla, and S. Sethi, Estimation of run time parameters of Compressed Air Engine Prototype, Anusandhan University, Orissa, International Journal of Enhanced Research in Scientific Technology and Engineering, 3(8), 2014, 108-112.

[21] Franco Antony, P.J. Albert, P.R.Rimin, Rino Disney, Sooraj M S and Sreevalsan S Menon, Design and Development of Pneumatic Hybrid Vehicle (PHV), International Journal of Innovative Research in Science, Engineering and Technology, 3(6), 2014, 13184-13191.

[22] K.Chavda, Patel Manish D, Suthar Umang P and Patel Krunal V, Study and Development of Compressed Air Engine-Single Cylinder: A Review Study, 2(5), 2014, 24-28.

[23] Ruchil A. Patel, A study on Compressed Air Engine: A Review, International Journal of Advanced Technology in Engineering and Science, 3(1), 2014, 192-196.

[24] S.A. Ahmad, N. Ahmad, S.J. Mansoor, S.F. Shah and S.M. A .Naqvi, Designing and Fabrication of Pollution

\section{Volume 4 Issue 12, December 2015}




\section{International Journal of Science and Research (IJSR) \\ ISSN (Online): 2319-7064}

Index Copernicus Value (2013): 6.14 | Impact Factor (2014): 5.611

Free Car, Journal of Quality and Technology Management, 10(2), 2014, 97-123.

[25] S.Pathak, K. Swetha, V. Shreedhar and V.S.V Prabhakar, ComVehicle: A Review, International Journal of Mechanical And Production Engineering, 2(4), 2014, 9-13.

[26] Y. W. Wang, J. J. You, C. K. Sung, and C. Y. Huang, The Application of Piston Type Compressed Air Engines On Motor Vehicles, Procedia Engineering, 79, 2014, 61-65.

[27] Ankit Sharma and Manpreet singh, Peramatric Analysis of an Air Driven Engine: A Critical Review, International Journal of Advance Research in Engineering and Technology, 6(4), 2015, 123-131.

[28] Bilal Abdullah Baig and Hakimuddin Hussain, Design and Fabrication of Compressed Air Powered Car, 3(2), 2015, 017-021.

[29] Mr. N.Govind, Mr.S.Sanyasi Rao and Mr.Manish kumar Behera, Design and Fabrication of Compressed Air Vehicle, International Journal \& Magazine of Engineering,Technology, Management and Research, 2(7), 2015, 219-223 